\title{
BreathEase: rationale, design and recruitment of a randomised trial and embedded mixed-methods study of a multiprofessional breathlessness service in early palliative care
}

\author{
Michaela Schunk $\mathbb{1}^{1,2}$, Ursula Berger ${ }^{2,3}$, Lien Le ${ }^{3}$, Eva Rehfuess ${ }^{2,3}$, Larissa Schwarzkopf $\mathbb{C}^{4,5}$, \\ Sabine Streitwieser ${ }^{1}$, Thomas Müller ${ }^{3}$, Miriam Hofmann $\mathbb{1}^{3}$, Rolf Holle ${ }^{2,4}$, Rudolf Maria Huber $\mathbb{C}^{6,7}$, \\ Ulrich Mansmann ${ }^{2,3}$ and Claudia Bausewein ${ }^{1}$
}

\begin{abstract}
${ }^{1}$ Dept of Palliative Medicine, LMU Hospital, LMU Munich, Munich, Germany. ${ }^{2}$ Pettenkofer School of Public Health, Munich, Germany. ${ }^{3}$ Faculty of Medicine, Institute for Medical Information Processing, Biometry and Epidemiology, LMU Munich, Munich, Germany. ${ }^{4}$ Health Economics and Health Care Management (IGM), Helmholtz Zentrum München GmbH, German Research Center for Environmental Health, Munich, Germany. ${ }^{5}$ Institut für Therapieforschung, Munich, Germany. ${ }^{6}$ Dept of Medicine V, LMU Hospital, LMU Munich, Munich, Germany. ${ }^{7}$ Member of the German Center of Lung Research (DZL, CPC-M), Munich, Germany.
\end{abstract}

Corresponding author: Michaela Schunk (michaela.schunk@med.uni-muenchen.de)

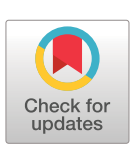

Copyright @The authors 2021

This version is distributed under the terms of the Creative Commons Attribution NonCommercial Licence 4.0. For commercial reproduction rights and permissions contact permissions@ersnet.org

Received: 29 April 2020 Accepted: 19 July 2021

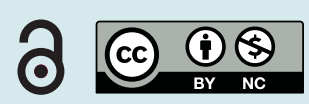

Shareable abstract (@ERSpublications)

The BreathEase study, a mixed-methods pragmatic RCT evaluating the Munich Breathlessness Service, included a heterogeneous sample that approximates real-world conditions of early palliative care, and ran qualitative and quantitative trial siblings https://bit.ly/375nCMO

Cite this article as: Schunk M, Berger U, Le L, et al. BreathEase: rationale, design and recruitment of a randomised trial and embedded mixed-methods study of a multiprofessional breathlessness service in early palliative care. ERJ Open Res 2021; 7: 00228-2020 [DOI: 10.1183/23120541.00228-2020].

\section{Abstract}

Background The Munich Breathlessness Service has adapted novel support services to the German context, to reduce burden in patients and carers from breathlessness in advanced disease. It has been evaluated in a pragmatic fast-track randomised controlled trial (BreathEase; NCT02622412) with embedded qualitative interviews and postal survey. The aim of this article is to describe the intervention model and study design, analyse recruitment to the trial and compare sample characteristics with other studies in the field.

Methods Analysis of recruitment pathways and enrolment, sociodemographic and clinical characteristics of participants and carers.

Results Out of 439 people screened, 253 (58\%) were offered enrolment and 183 (42\%) participated. n=97 (70\%) carers participated. 186 (42\%) people did not qualify for inclusion, mostly because breathlessness could not be attributed to an underlying disease. All participants were self-referring; $60 \%$ through media sources. Eligibility and willingness to participate were associated to social networks and illness-related activities as recruitment routes. Mean age of participants was 71 years (51\% women), with COPD (63\%), chronic heart failure (8\%), interstitial lung disease (9\%), pulmonary hypertension (6\%) and cancer (7\%) as underlying conditions. Postal survey response rate was $89 \%$. Qualitative interviews were conducted with 16 patients and nine carers.

Conclusion The BreathEase study has a larger and more heterogeneous sample compared to other trials. The self-referral-based and prolonged recruitment drawing on media sources approximates real-world conditions of early palliative care. Integrating qualitative and quantitative components will allow a better understanding and interpretation of the results of the main effectiveness study.

\section{Introduction}

Breathlessness is a common, distressing symptom in advanced cardiorespiratory and malignant diseases, which reduces both patient and carer quality of life (QoL), psychological wellbeing and functional status [1, 2]. The complexity of the symptom is exemplified by the inconsistent relationship between the underlying disease and breathlessness perception, and by the wide range of multiple interacting factors influencing symptom perception, including reactions to breathlessness, such as avoidance behaviour, that may worsen 
symptom perception [3, 4]. Even while receiving best-practice medical treatment of the underlying condition, chronic breathlessness inflicts increased costs on the health system, such as for emergency care during episodes of acute breathlessness [5, 6].

Optimising management of chronic breathlessness draws on a variety of mostly nonpharmacological approaches to support patients and their families in developing strategies for adaptive self-management [7-9]. Breathlessness support services, led by palliative medicine, have been developed in the United Kingdom (UK), building upon theoretical work, modelling and feasibility studies [10]. The Cambridge Breathlessness Intervention Service (CBIS) and the London Breathlessness Support Service (BSS) provide face-to-face support either at home or in outpatient clinics or through a combination of both, with varied treatment schedules and multiprofessional input, but very similar intervention components [7, 8]. Their effectiveness in terms of alleviating symptom distress, strengthening symptom mastery and increasing QoL was demonstrated in three pragmatic randomised controlled trials (RCTs) [11-13].

The Munich Breathlessness Service (MBS) has adapted the interventions of CBIS and BSS to the German context. Compared with the UK, specialists in private practices outside hospitals provide broader access to respiratory services in Germany. However, a qualitative study has pointed to healthcare providers' lack of awareness regarding the symptom burden and therapeutic concepts [14]. Drawing on experiences from the UK, a more intense and longer intervention was considered appropriate and tested in the MBS, notably emphasising physiotherapy.

The MBS has been evaluated in the BreathEase study, testing the (cost-)effectiveness of the MBS on mastery of breathlessness and QoL in patients with advanced disease within a RCT design. The main results of this RCT have been published elsewhere [15]. This paper focuses on the recruitment and enrolment strategies of the BreathEase study and their impact on the sample characteristics, and appraises the study design and outcome measurements with its embedded quantitative and qualitative components.

In this paper, we 1) describe the full study design and rationale behind the intervention; 2) analyse recruitment and enrolment into the study; and 3) compare the sample characteristics at baseline with the CBIS and BSS studies.

Methods

Drawing on a system-based logic model of the MBS intervention, the BreathEase study design and data collection are described, encompassing the RCT and embedded studies.

\section{Design}

We conducted a fast-track pragmatic observer-blinded RCT. Participants randomised in the control group received the intervention after a waiting period of 8 weeks. Enrolment started in March 2014, ending in October 2018. The study was registered with ClinicalTrials.gov (NCT02622412). Within the RCT, we embedded qualitative interviews and a postal survey to explore study participants' views regarding the intervention (figure 1). Approval was obtained from the research ethics committee at the medical faculty of Ludwig Maximilian University Munich (Munich, Germany) (no. 523-14).

\section{Intervention}

The MBS is run as a multiprofessional outpatient clinic at the department of palliative medicine in cooperation with the respiratory department, both at Munich University Hospital. Patients have up to two outpatient appointments at the hospital with palliative medicine clinicians and three or four physiotherapy treatments at a community-based practice within 5-6 weeks. Further input by the multiprofessional team (e.g. respiratory specialist, psychologist, social worker) is available as needed. During the trial period, all those requesting to use the service were asked to participate in the trial.

Following the template of RoHwer et al. [16], a system-based logic model of the intervention was developed to illustrate the complex relationships between individual characteristics, the intervention and its delivery, and contextual factors, based on reviews of existing breathlessness services, focused literature searches and within-team brainstorming (figure 2). Central to the model depicted in figure 2 is a set of concepts that describe the impact of breathlessness, define the composition and delivery of the intervention and the influence of a range of other factors [3, 6, 8, 9, 17-19]. Most influential with respect to the theory underlying the intervention is the Breathing-Thinking-Functioning model of SpaTHIs et al. [3], which is the basis for classifying the diverse service components. We postulate two mechanisms of change: first, the intervention is predicted to affect cognitive and behavioural reactions to breathlessness, which enhance self-management through meaning-based coping, improved problem management and emotional regulation 


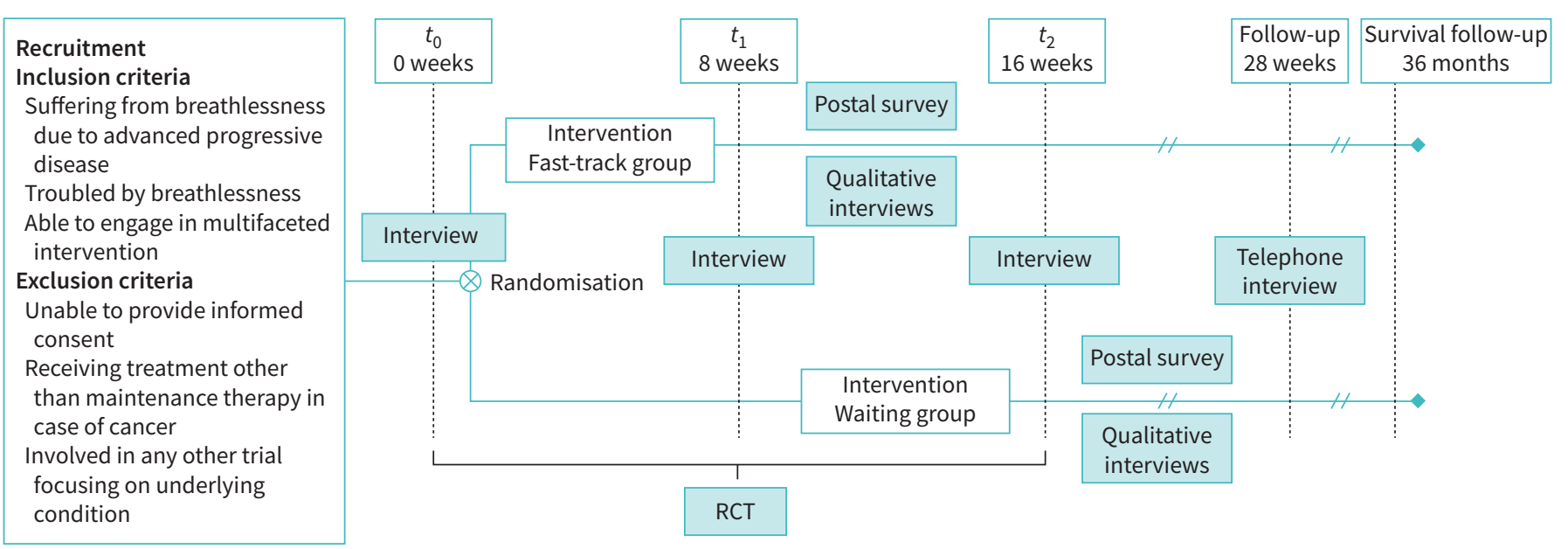

FIGURE 1 BreathEase study design. t: time; RCT: randomised controlled trial.

[6, 20-22]. Second, the intervention supports patients' "adaptive work" in chronic illness [17]. This is achieved by offering recognition through a holistic assessment and encouragement to utilise community-based health services following the short-term MBS intervention, e.g. lung exercise groups, advanced care planning.

\section{Recruitment}

The study received media coverage on the radio and a local television station. Short articles in local newspapers were released throughout the study, to increase public awareness and self-referral. Information was provided to local practice-based respiratory specialists and hospitals specialising in respiratory patients, as well as several cardiologists. The service was presented to two local self-help groups, one for patients with COPD and one for patients with pulmonary arterial hypertension (PAH), one hospital-based sports

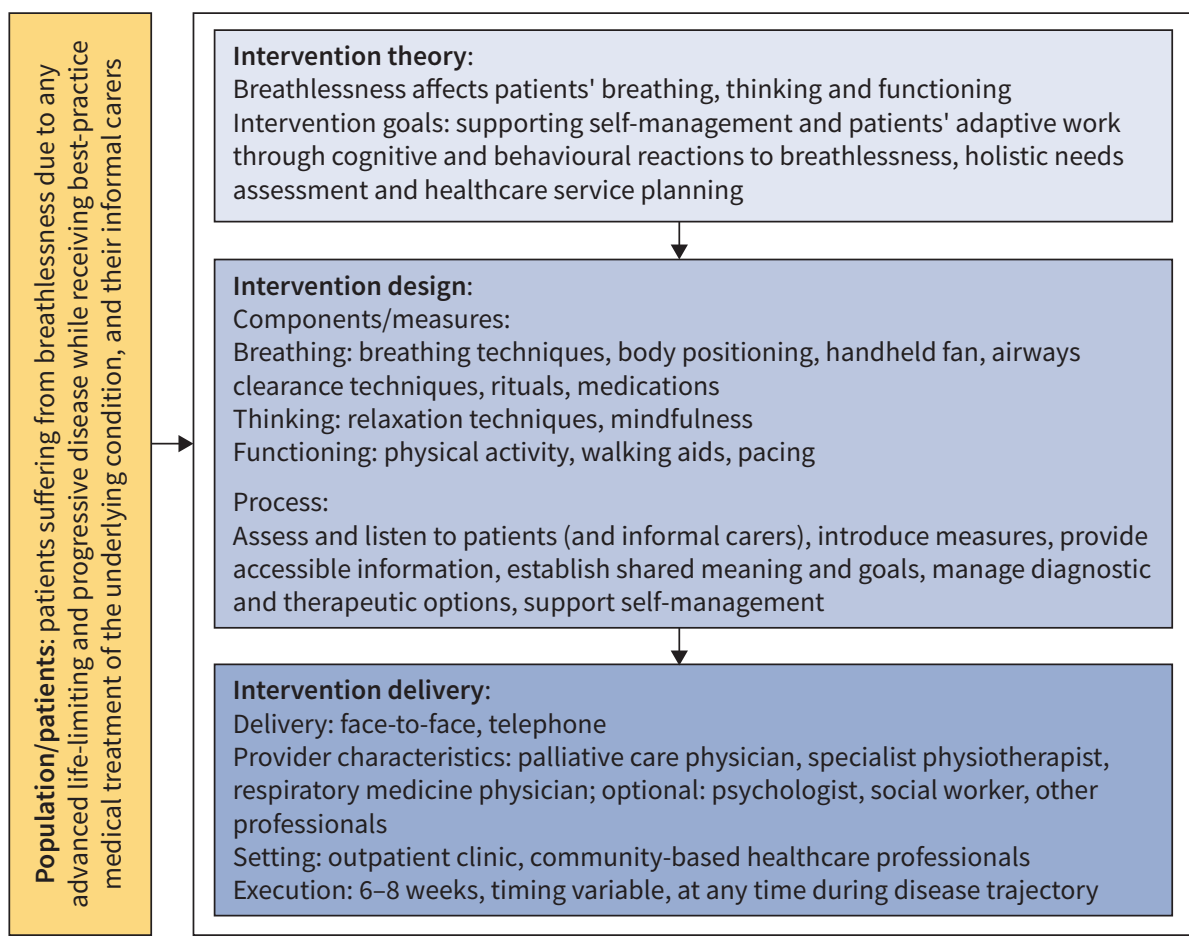

\section{Outcomes:}

Breathlessness mastery

Breathlessness burden and distress

Coping with breathlessness crisis

Long-term outcomes:

Depression and anxiety

Quality of life

Functional status

Emotional wellbeing

Undesired outcomes:

Emergency situations

Over-utilisation of services

High treatment burden

Non-health outcomes:

Cost-effectiveness

\section{Influencing factors:}

Health service availability, quality, accessibility

Healthcare provider culture and values

Financial, social resources

Self-help networks/community support

Healthcare policy and financing

Legal framework

FIGURE 2 Logic model of Munich Breathlessness Service (MBS) intervention. 
group (PAH) and a respiratory medicine network. Leaflets were distributed regularly within the hospital and at various contact points throughout the city.

The trial operated on the basis of self-referral by the patients themselves, although in some cases information was received by clinicians (referred to as "clinical referral"). Eligibility was based on up-to-date information (the past 6 months) from doctors' letters provided by those interested in participation and assessed by the clinical investigator. Doctors' letters were not requested when exclusion criteria could be established by the study coordinator beforehand.

\section{Participants}

RCT

Broad inclusion and minimal exclusion criteria were employed to approximate real-world conditions of early palliative care (figure 1).

If people were suffering from acute exacerbations of the underlying condition at the time of recruitment, they were put on a waiting list after eligibility was established and subsequently entered the trial. Eligible individuals were asked whether they had a close family member or friend, defined as someone with almost daily contact. If this was the case, the so-called “carer” was also asked to participate in the study.

Recruitment pathways were classified according to 1) media, 2) clinical referral and 3) social network/ illness-related activities. Recruitment outcomes were defined as 1) enrolment, 2) declined consent or 3) not eligible. Reasons for exclusion were categorised according to inclusion and exclusion criteria.

\section{Postal survey}

All RCT study participants were invited to participate after completing the intervention.

\section{Qualitative interviews}

A purposeful sample of 25 study participants (patients and carers) was drawn from the RCT sample after completion of the intervention, with age, gender, type of underlying disease and existence of a carer as sampling criteria.

\section{Data collection}

RCT

Age, gender and the extent to which breathlessness impacts daily activities, measured with the modified Medical Research Council dyspnoea scale (mMRC) [23], were recorded for all those screened for study participation, as well as recruitment routes. Study participant characteristics were assessed at baseline. Patients' diagnoses were recorded as documented in doctors' letters, including grading the severity of the illness according to the Global Initiative for Chronic Obstructive Lung Disease spirometric classification [24] and the New York Heart Association classification of heart failure [25].

Outcomes were measured with standardised self-administered questionnaires at $t_{0}=$ baseline (prior to randomisation), $t_{1}$ =week 8 from $t_{0}, t_{2}=$ week 16 from $t_{0}$ and follow-up (week 28 from $t_{0}$ ) (figure 1). To reduce burden for study participants, home visits by a qualified study nurse were offered to collect the data at $t_{0}-t_{2}$; follow-up was organised by telephone interview. Recruitment, enrolment and baseline data collection were pre-tested in a pilot study with eight participants. Data were entered in an electronic record system.

\section{Postal survey and qualitative interviews}

The 23-item questionnaire was sent out 4-6 weeks after completion of the intervention. Semi-structured interviews were conducted 4-6 weeks after completion of the intervention and, if possible, after completion of the postal survey.

Data were checked with double entry on randomly selected data subsets.

\section{Variables and outcomes}

Study participant characteristics included age, sex, underlying disease and comorbidities, education, presence and tasks of the carer, marital status and household composition. Comorbidity was assessed using the Charlson Comorbidity Index [26] and functional performance using the Australia-modified Karnofsky Performance Scale [27]. 
The RCT had four primary outcomes; mastery of breathlessness and QoL were both measured on the validated Chronic Respiratory Disease Questionnaire (CRQ) [28]. Palliative care needs and specific symptoms were assessed using the validated German version of the Integrated Palliative Care Outcome Scale (IPOS) [29, 30]. Carer burden was assessed with the Zarit Burden Interview [31].

Secondary outcomes included the numerical rating scale on the strength of breathlessness (on average, at rest and on exertion during the past $24 \mathrm{~h}$ ), lung function, the Hospital Anxiety and Depression Scale, the Short Physical Performance Battery, QoL assessed using the German tariff of EQ-5D-5L [32] and the FIMA questionnaire on health service utilisation and medication [33].

Carer QoL was assessed with the EQ-5D-5L and supplemented by three items concerning insomnia and sleep quality. All adverse events defined as any unfavourable medical occurrence (e.g. infections, hospital admissions) were recorded throughout the trial. Survival was followed-up for all participants until the end of the study. All outcomes are depicted in table 1.

The postal survey addressed the perceived benefit of recommendations, materials and exercises provided as well as overall satisfaction with the MBS, its accessibility and scope and participation in the study. Topics of the qualitative interviews were the perception of symptom burden, coping mechanisms and whether or not attendance of the MBS was successful in supporting longer term self-management capacities.

\section{Sample size calculation}

The study's hypotheses involve changes in the four primary outcomes outlined earlier. To detect a mean difference of 0.45 in the change score of CRQ QoL and CRQ mastery of breathlessness with a standard deviation of 1 [28] at a significance level of $\alpha=0.05$ and a power of $80 \%, 80$ participants were required per group. Based on the London BSS trial, a conservative calculation estimated the uptake into the trial to be $\sim 50 \%$ of referred participants and attrition to be $25 \%$, resulting in a planned screening of 430 people in order to recruit a total of 160 participants into the study.

\section{Data analysis of recruitment, enrolment and sample characteristics}

Recruitment pathways, recruitment outcome and time for screening are descriptively analysed. Reasons for exclusion are mapped by type and frequency. Logistic regression models are used to assess the effects of gender, age, breathlessness (mMRC) and recruitment route on 1) eligibility (yes/no) and 2) consent to

TABLE 1 Overview of quantitative outcomes and associated measures

\begin{tabular}{|c|c|c|c|c|c|}
\hline & $\begin{array}{c}t_{0} \\
\text { (baseline) }\end{array}$ & $\begin{array}{c}t_{1} \\
\text { (8 weeks) }\end{array}$ & $\begin{array}{c}t_{2} \\
\text { (16 weeks) }\end{array}$ & $\begin{array}{l}\text { Follow-up } \\
\text { (28 weeks) }\end{array}$ & $\begin{array}{l}\text { End of } \\
\text { study }\end{array}$ \\
\hline $\mathrm{CRQ}^{\#}$ & $x$ & $x$ & $x$ & $x$ & \\
\hline IPOS $^{\natural 1}$ & $x$ & $x$ & $x$ & $x$ & \\
\hline NRS breathlessness ${ }^{+}$ & $x$ & $x$ & $x$ & $x$ & \\
\hline $\mathrm{HADS}^{\S}$ & $x$ & $x$ & $x$ & $x$ & \\
\hline EQ-5D-5L, VAS & $x$ & $\mathrm{x}$ & $x$ & $x$ & \\
\hline SPPB $^{f}$ & $x$ & $x$ & $x$ & & \\
\hline Lung function & $x$ & $x$ & $x$ & & \\
\hline Oxygen saturation & $x$ & $x$ & $\mathrm{x}$ & & \\
\hline $\begin{array}{l}\text { Health service utilisation and } \\
\text { medication (FIM-P) }\end{array}$ & $x$ & $x$ & $x$ & $x$ & \\
\hline Patient survival & & & & & $x$ \\
\hline Adverse events & $x$ & $x$ & $x$ & $x$ & \\
\hline Carer Zarit Burden Inventory & $x$ & $x$ & $x$ & & \\
\hline Carer EQ-5D-5L, VAS & $x$ & $x$ & $x$ & & \\
\hline Carer sleep quality & $x$ & $x$ & $x$ & & \\
\hline \multicolumn{6}{|c|}{ 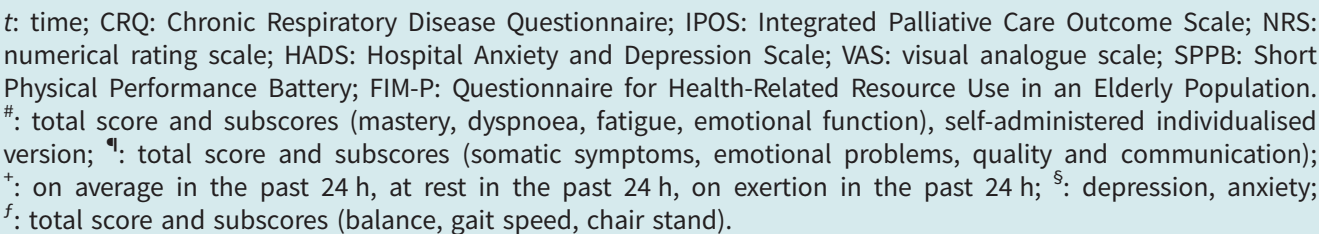 } \\
\hline
\end{tabular}


participation (yes/no). Study participant and carer characteristics are described in total and for women and men seperately (mean \pm SD). Missing data are reported.

\section{Results}

\section{Recruitment and enrolment}

From February 2015 to October 2018, we screened 439 people; of those, 253 (58\%) were offered enrolment and 183 (42\%) were successfully recruited. Trial length was 3.5 years, 2 years longer than planned. Media recruitment was the most common route in the total screened (58\%) and in those enrolled (44\%). However, enrolment was most successful in people recruited via social network/illness-related activities and least successful in those recruited via the media. Recruitment routes in comparison to recruitment outcome are shown in table 2 . In our sample, the overall attrition during the screening process was $n=256$ (58\%) of the total $n=439$, which is higher than the estimated $50 \%$ before the trial.

We did not limit the length of time for screening for each individual. The time for screening for those who declined participation was longest on average (mean \pm SD $113 \pm 165$ days, median 51 days, range 0-997 days), compared to 50 \pm 70 days (28 days, 0-626 days) from those enrolled and $66 \pm 106$ days (26 days, range $0-843$ days) for those not eligible. When looking at the time for screening by recruitment routes, the largest share of decision processes for those getting in touch via the media route was 2-6 months (41\%), compared to the clinical and social network referral routes, where most had completed the decision processes by 1 month (43\% and 47\%, respectively) (figure 3). Almost a fifth of those approaching the study via the media route $(n=48,19 \%)$ were decided within 5 days. With one exception, these were all people who met an exclusion criterion.

Figure 4 shows reasons for exclusion, including overlaps between categories. An underlying medical condition that could not be ascertained was the most frequent cause of exclusion (39\%). The defining disease had to be causally linked to symptom breathlessness, and it had to be a life-limiting progressive disease, such as COPD or interstitial lung disease (ILD), which would qualify palliative care services for attending to these patient. 35\% of patients interested in the MBS did not meet these criteria or were not receiving best-practice medical treatment. Owing to slow recruitment, all potentially eligible participants were followed-up by prolonged efforts, often associated with logistical issues, such as transportation problems, or with difficulties in getting hold of up-to-date information on their medical conditions. Organisational reasons applied to about one-third of patients; in $\mathrm{n}=30$ they were the only reason for exclusion.

Patient characteristics were analysed with regard to fulfilling the inclusion criteria and exclusion requirements and with regard to choosing to decline enrolment, following the offer (table 3). Younger

\begin{tabular}{|c|c|c|c|c|}
\hline & Enrolment & $\begin{array}{l}\text { Declined } \\
\text { consent }\end{array}$ & $\begin{array}{l}\text { Not } \\
\text { eligible }\end{array}$ & $\begin{array}{c}\text { Total } \\
\text { screened }\end{array}$ \\
\hline Participants, n (\%) & $183(42)$ & $70(16)$ & $186(42)$ & $439(100)$ \\
\hline Newspaper, $\mathrm{n}$ & 73 & 35 & 112 & 220 \\
\hline Television/radio, $\mathrm{n}$ & 6 & 4 & 13 & 23 \\
\hline Internet, $\mathrm{n}$ & 2 & 2 & 10 & 14 \\
\hline Media (total), n (row \%, column \%) & $81(32,44)$ & $41(16,60)$ & $135(53,73)$ & $257(100,58)$ \\
\hline Hospital & 29 & 11 & 14 & 54 \\
\hline Primary-care physician & 10 & 5 & 6 & 21 \\
\hline Practice-based specialist & 8 & 4 & 4 & 16 \\
\hline Clinical referral (total), $\mathrm{n}$ (row \%, column \%) & $47(52,26)$ & $20(22,29)$ & $24(26,13)$ & $91(100,21)$ \\
\hline Self-help/lung sport groups & 19 & 2 & 0 & 21 \\
\hline Friends/social network & 12 & 1 & 6 & 19 \\
\hline Leaflet (hospital) & 8 & 0 & 8 & 16 \\
\hline Leaflet (unspecified) & 7 & 0 & 3 & 10 \\
\hline Open day (e.g. cancer help) & 4 & 3 & 1 & 8 \\
\hline $\begin{array}{l}\text { Social network/illness-related activities (total), n } \\
\quad(\text { row } \% \text {, column \%) }\end{array}$ & $50(68,27)$ & $6(8,8)$ & $18(24,10)$ & $74(100,17)$ \\
\hline Missing, $n$ & 5 & 3 & 9 & $17(4)$ \\
\hline
\end{tabular}


a)

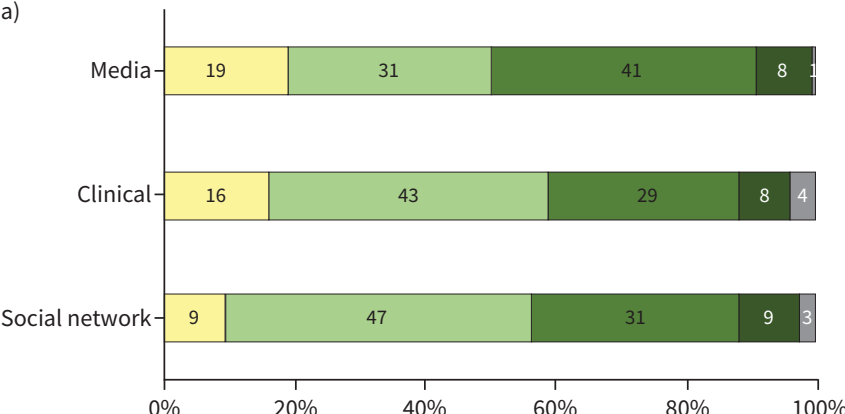

Up to 5 days $\square$ Up to 1 month

2-6 months

6-12 months

$>12$ months

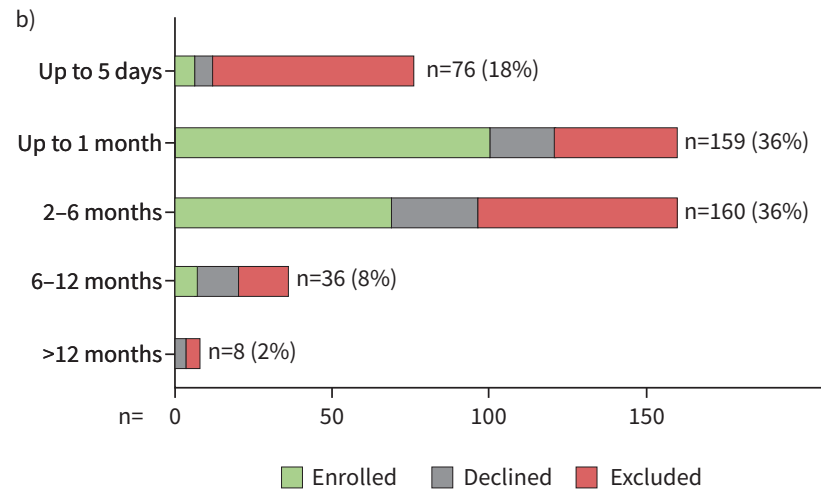

FIGURE 3 Screen times by a) recruitment route and b) recruitment outcome.

( $<60$ years) and older ( $>80$ years) age, as well as moderate symptom burden (mMRC=1) was significantly associated with a lower chance of being considered eligible to participate. Recruitment via social networks and via clinical referral were associated with higher chances of eligibility. Furthermore, people recruited via social networks were less likely to decline compared to people recruited via media information. Compared to men, women declined enrolment more often.

The postal survey was sent out to 149 study participants and yielded 132 (89\% response rate) responses. Qualitative interviews were conducted with 25 study participants, i.e. 16 patients and nine carers. Two study participants and one carer declined participation in the qualitative study without giving reasons; one study participant died before the interview was scheduled.

\section{Sample characteristics}

Table 4 characterises the study participants and carers. Most patients (49\%) were in the age group 70-79 years. Sex distribution was almost equal. Half the sample (53\%) were married, 61\% were living

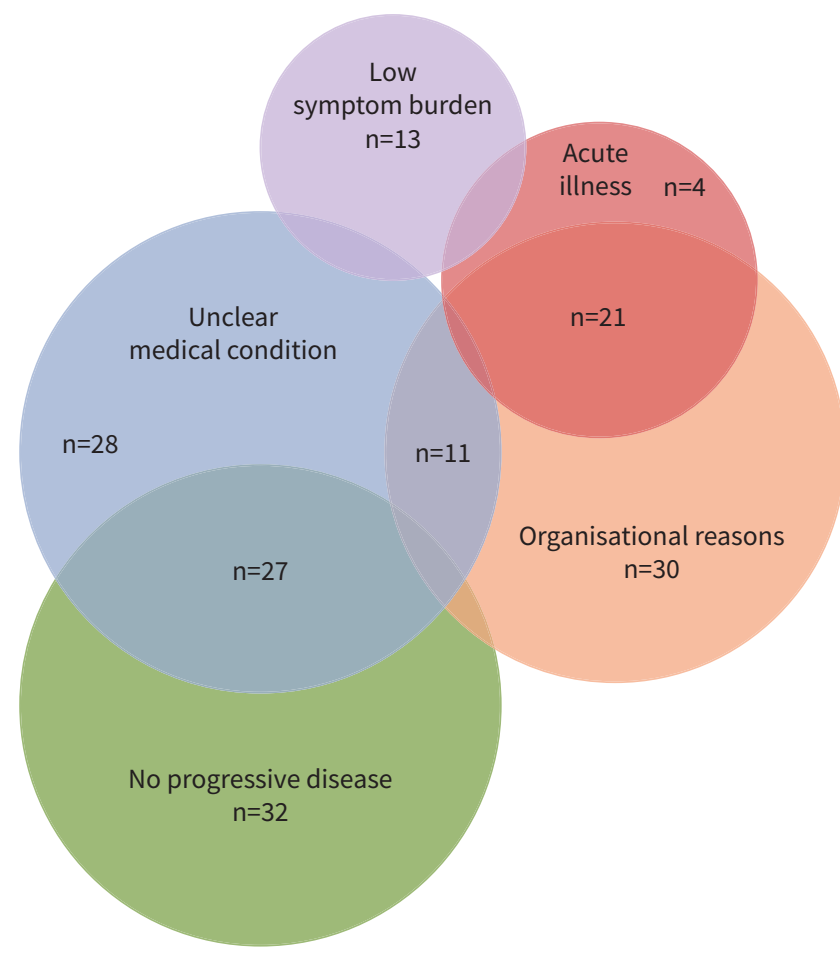

Total exclusions $(n=186)^{\#}$

- Underlying medical condition could not be ascertained $n=72(39 \%)$

- Nonmedical organisational reasons, e.g. lives outside study

catchment area, contact broken off $n=67(36 \%)$

- No progressive and advanced life-limiting disease causing breathlessness,

or not receiving best practice medical treatment $n=66(35 \%)$

- Acute illness or currently in hospital/rehabilitation $n=31(17 \%)$

- Low symptom burden $n=17(9 \%)$

- Cognitive impairment $n=10(5 \%)$

- Insufficient German to participate in study $n=4(2 \%)$

- Cancer patients with treatment other than maintenance therapy $n=3(2 \%)$

- Participation in other clinical trial focusing on underlying condition $n=0$

FIGURE 4 Reasons for exclusion. Minor overlaps in Venn diagram are not reported. Venn diagram: https://www.biovenn.nl/. \#: multiple answers possible. 
TABLE 3 Patient characteristics by recruitment outcome

\begin{tabular}{|c|c|c|c|c|c|c|c|}
\hline & Total & Eligible & $\begin{array}{c}\text { Not } \\
\text { eligible }\end{array}$ & $\begin{array}{l}\text { Modelling eligibility } \\
\text { OR }(95 \% \mathrm{Cl})^{\#}\end{array}$ & Enrolled & Declined & $\begin{array}{l}\text { Modelling enrolment } \\
\text { OR }(95 \% \mathrm{CI})^{4}\end{array}$ \\
\hline Participants, $\mathrm{n}$ & 439 & 253 & 186 & & 183 & 70 & \\
\hline \multicolumn{8}{|l|}{ Age groups $^{+}, \mathrm{n}(\%)$} \\
\hline$<60$ years & $45(10)$ & $19(8)$ & $26(15)$ & $0.32(0.15-0.71)^{\star *}$ & $17(9)$ & $2(3)$ & $4.71(0.58-38.19)$ \\
\hline $60-69$ years & $97(22)$ & $68(27)$ & $29(17)$ & $1.20(0.68-2.12)$ & $52(28)$ & $16(24)$ & $0.91(0.43-1.90)$ \\
\hline 70-79 years (ref.) & $197(45)$ & $124(50)$ & $73(42)$ & Ref. & $90(49)$ & $34(52)$ & Ref. \\
\hline$>80$ years & $82(19)$ & $38(15)$ & $44(26)$ & $0.39(0.22-0.70)^{\star \star}$ & $24(13)$ & $14(21)$ & $0.49(0.21-1.15)$ \\
\hline Female, n (\%) & $237(54)$ & $138(55)$ & $99(53)$ & $1.10(0.71-1.71)$ & $93(51)$ & $45(64)$ & $0.47(0.25-0.88)^{\star}$ \\
\hline Male (ref.), n (\%) & & $115(45)$ & $87(47)$ & Ref. & $90(49)$ & $25(36)$ & Ref. \\
\hline \multicolumn{8}{|l|}{$\mathrm{mMRC}^{\S}, \mathrm{n}(\%)$} \\
\hline $1=$ moderate & 85 (19) & $25(10)$ & $60(33)$ & $0.27(0.15-0.52)^{\star \star \star}$ & $16(9)$ & $9(13)$ & $0.50(0.18-1.41)$ \\
\hline 2=strong (ref.) & $134(31)$ & $85(34)$ & $49(27)$ & Ref. & $68(37)$ & $17(25)$ & Ref. \\
\hline 3=very strong & $214(49)$ & $142(56)$ & $72(40)$ & $0.90(0.54-1.49)$ & $99(54)$ & $43(62)$ & $0.83(0.41-1.67)$ \\
\hline \multicolumn{8}{|l|}{$\begin{array}{l}\text { Recruitment route }{ }^{f} \text {, } \\
\text { n (\%) }\end{array}$} \\
\hline Media (ref.) & $257(58)$ & $122(50)$ & $135(76)$ & Ref. & $81(46)$ & $41(61)$ & Ref. \\
\hline Clinical & $91(21)$ & $67(27)$ & $24(14)$ & $2.82(1.55-5.14)^{\star \star \star}$ & $47(26)$ & $20(30)$ & $1.07(0.52-2.18)$ \\
\hline Social & $74(17)$ & $56(23)$ & $18(10)$ & $3.15(1.67-5.94)^{\star \star \star}$ & $50(28)$ & $6(9)$ & $4.76(1.70-13.38)^{\star \star}$ \\
\hline \multicolumn{8}{|c|}{ 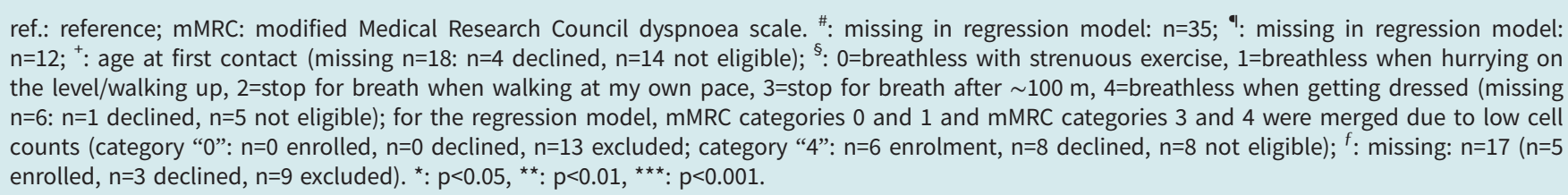 } \\
\hline
\end{tabular}

with a partner/others and $75 \%$ had a carer. Men in the sample, compared to women, were more often married (73\% versus 33\%), living with others (77\% versus $46 \%$ ) and had a carer (87\% versus $65 \%$ ). Approximately two-thirds of study participants suffered from COPD (63\%) as the underlying condition. Other diseases were chronic heart failure (8\%), ILD (9\%), pulmonary hypertension (6\%), cancer (7\%) and diseases such as bronchiectasis or emphysema. Most study participants were rated on the Australian Karnofsky scale as having some symptoms that limited their normal activity (80\%) or as not being able to carry out normal activity (70\%). 97 carers (67\% female), mostly participants' partners (87\%), were included in the study with a mean age of 66.3 years. Caring tasks extended from $<10 \mathrm{~h}$ per week (61\%) to $>50 \mathrm{~h}$ per week $(9 \%)$, with female carers spending more time per week with caring activities, compared to male carers.

\section{Discussion}

BreathEase is a pragmatic fast-track observer-blinded RCT and embedded mixed-methods study, assessing the effectiveness of the MBS for patients with advanced disease.

Two pioneer breathlessness services in the UK have been tested in three effectiveness trials indicating benefits, albeit by a small margin [11-13]. This may result from methodological difficulties of pragmatic trials. Studies in such settings are very valuable for their high external validity and applicability to routine practice; however, they need increased sample sizes to deliver robust estimates [34]. Despite realistic sample size calculations, challenges of recruitment are often underestimated, and trials do not achieve the target sample size [31]. BreathEase has managed to attain the predetermined sample size, with prolonged recruitment. To date, it represents the largest study evaluating a breathlessness service.

\section{Sample characteristics compared with other studies}

The BreathEase sample is broadly representative of the target population of patients with a high symptom burden despite optimal treatment of the underlying (progressive, life-limiting) disease. Our sample is more heterogeneous than other trials in terms of underlying diseases. Our sample has more patients with COPD (68\%) than the study of Higginson et al. [13] (52\%), but fewer than that of FARQuHAR et al. [12] (85\%). No other studies included patients with chronic heart failure or pulmonary hypertension, but there was a greater proportion of cancer and ILD patients in the study by HigGINSON et al. [13] (cancer 21\% compared with $7 \%$ in our sample; ILD 18\% compared with $9 \%$ in our sample). One of the trials exclusively enrolled patients with cancer [11]. Men and women are represented in almost equal numbers in the BreathEase 


\begin{tabular}{|c|c|c|c|}
\hline & Total & Women & Men \\
\hline Patients, $\mathrm{n}$ & 183 & 93 & 90 \\
\hline Age, years mean \pm sD (range) & $71.3 \pm 8.6(39.5-94.2)$ & $70.6 \pm 8.8(39-94)$ & $71.1 \pm 8.5(41-90)$ \\
\hline \multicolumn{4}{|l|}{ Age groups } \\
\hline$<60$ years & $17(9)$ & $8(9)$ & $9(10)$ \\
\hline $60-69$ years & $51(28)$ & $26(28)$ & $25(28)$ \\
\hline 70-79 years & $90(49)$ & $47(51)$ & $42(48)$ \\
\hline$>80$ years & $25(13)$ & $12(13)$ & $13(14)$ \\
\hline \multicolumn{4}{|l|}{ Sex } \\
\hline Female & $93(50.8)$ & & \\
\hline \multicolumn{4}{|l|}{ Marital status } \\
\hline Married & $97(53)$ & $31(33)$ & $66(73)$ \\
\hline Single & $25(14)$ & $16(17)$ & $9(10)$ \\
\hline Widowed & $30(16)$ & $25(27)$ & $5(6)$ \\
\hline Divorced/separated & $31(17)$ & $21(23)$ & $10(11)$ \\
\hline \multicolumn{4}{|l|}{ Household composition } \\
\hline Living alone & $71(39)$ & $50(54)$ & $21(23)$ \\
\hline Living with partner/others & $112(61)$ & $43(46)$ & $69(77)$ \\
\hline Carer & $138(75)$ & $60(65)$ & $78(87)$ \\
\hline \multicolumn{4}{|l|}{ Education } \\
\hline 9 years & $69(38)$ & $35(38)$ & $34(38)$ \\
\hline 10 years & $66(36)$ & $40(43)$ & $26(29)$ \\
\hline $12-13$ years & $48(26)$ & $18(19)$ & $30(33)$ \\
\hline \multicolumn{4}{|l|}{ Diagnosis } \\
\hline COPD $^{\#}$ & $115(63)$ & $63(68)$ & $52(58)$ \\
\hline Stage I & $5(4)$ & $3(5)$ & $2(4)$ \\
\hline Stage II & $33(29)$ & $18(29)$ & $15(29)$ \\
\hline Stage III & $34(30)$ & $18(29)$ & $16(31)$ \\
\hline Stage IV & $43(37)$ & $24(38)$ & $19(37)$ \\
\hline Chronic heart failure & $14(8)$ & $5(5)$ & $9(10)$ \\
\hline NYHA I & $1(7)$ & 0 & $1(11)$ \\
\hline NYHA II & $5(36)$ & $2(40)$ & $3(33)$ \\
\hline NYHA III & $7(50)$ & $2(40)$ & $5(56)$ \\
\hline NYHA IV & $1(7)$ & $1(20)$ & 0 \\
\hline Interstitial lung disease & $17(9)$ & $5(5)$ & $12(13)$ \\
\hline Pulmonary hypertension & $10(6)$ & $6(6)$ & $4(4)$ \\
\hline Cancer $^{+}$ & $13(7)$ & $6(6)$ & $7(8)$ \\
\hline Other & $14(8)$ & $8(9)$ & $6(7)$ \\
\hline \multicolumn{4}{|l|}{$\begin{array}{l}\text { Australia-modified Karnofsky Performance } \\
\text { Scale }\end{array}$} \\
\hline $90 \%$ (minor symptoms) & $18(10)$ & $11(8)$ & $7(8)$ \\
\hline $80 \%$ (some symptoms) & $75(41)$ & $37(40)$ & $38(42)$ \\
\hline $70 \%$ (unable to perform normal activity) & $59(32)$ & $30(32)$ & $29(32)$ \\
\hline $60 \%$ (occasional assistance) & $24(13)$ & $12(13)$ & $12(13)$ \\
\hline 50\% (considerable assistance) & $6(3)$ & $3(3)$ & $3(3)$ \\
\hline $40 \%$ (bed $50 \%$ time) & $1(1)$ & 0 & $1(1)$ \\
\hline Charlson Comorbidity Index ${ }^{\S}$ mean \pm sD; range & $1.6 \pm 1.7(0-8)$ & $1.5 \pm 1.5$ & $1.7 \pm 1.8$ \\
\hline Carers $^{f}, \mathrm{n}$ & 97 & 66 & 31 \\
\hline Age, years mean \pm sD (range) & $66.3 \pm 12.0(29-86)$ & $64.1 \pm 12.6(36-85)$ & $70.2 \pm 10.2(29-86)$ \\
\hline \multicolumn{4}{|l|}{ Age groups } \\
\hline$<60$ years & $23(28)$ & $18(34)$ & $5(17)$ \\
\hline $60-69$ years & $21(25)$ & $12(23)$ & $9(30)$ \\
\hline $70-79$ years & $33(40)$ & $21(40)$ & $12(40)$ \\
\hline$>80$ years & $6(7)$ & $2(4)$ & $4(13)$ \\
\hline Female & $66(68)$ & & \\
\hline \multicolumn{4}{|l|}{ Education } \\
\hline 9 years & $37(38)$ & $23(37)$ & $14(45)$ \\
\hline 10 years & $24(25)$ & $18(29)$ & $6(19)$ \\
\hline $12-13$ years & $33(34)$ & $22(35)$ & $11(35)$ \\
\hline
\end{tabular}




\begin{tabular}{|c|c|c|c|}
\hline & Total & Women & Men \\
\hline \multicolumn{4}{|l|}{ Carer marital status } \\
\hline Married & $80(85)$ & $54(86)$ & $26(84)$ \\
\hline Single & $7(7)$ & $5(8)$ & $2(6)$ \\
\hline Divorced/separated & $7(7)$ & $4(6)$ & $3(10)$ \\
\hline \multicolumn{4}{|l|}{ Carer relationship to patient } \\
\hline Partner & $72(75)$ & $48(75)$ & $24(77)$ \\
\hline Child/other & $23(25)$ & $16(25)$ & $7(23)$ \\
\hline \multicolumn{4}{|l|}{ Care activities } \\
\hline$<10 \mathrm{~h}$ per week & $53(61)$ & $30(53)$ & $23(77)$ \\
\hline$\geqslant 10$ and $<20 \mathrm{~h}$ per week & $7(8)$ & $7(12)$ & 0 \\
\hline$\geqslant 20$ and $<50 \mathrm{~h}$ per week & $19(22)$ & $14(25)$ & $5(17)$ \\
\hline$\geqslant 50 \mathrm{~h}$ per week & $8(9)$ & $6(11)$ & $2(7)$ \\
\hline \multicolumn{4}{|c|}{$\begin{array}{l}\text { Data are presented as } n(\%) \text {, unless otherwise stated. NYHA: New York Heart Association. }{ }^{\#} \text { : Global Initiative for } \\
\text { Chronic Obstructive Lung Disease spirometric classification for airflow limitation based on post-bronchodilator } \\
\text { forced expiratory volume in } 1 \mathrm{~s} \text {; }{ }^{\uparrow} \text { : NYHA functional classification; }{ }^{+}: \text {site of carcinoma: lung } n=8 \text {, uterus } n=1 \text {, } \\
\text { bladder } n=1 \text {, other } n=3 \text {; }{ }^{\text {: }} \text { scale range: } 0-37 \text { best-worst; }{ }^{f}: \text { missing data: carer age } n=14 \text {, carer education } n=3 \text {, } \\
\text { carer marital status } n=3 \text {, carer residence } n=2 \text {, carer relationship } n=2 \text {, care activities } n=10 \text {. }\end{array}$} \\
\hline
\end{tabular}

sample, which is noteworthy, as the prevalence and incidence of illnesses such as COPD is higher in men [35]. Women's perception of symptom burden may be higher [36] and there may be gender-related differences in that women find it easier to seek help [37].

Underlying diseases and baseline values of symptom- and illness-related burden are important sample characteristics, just like age and gender, which may affect the outcome of the intervention. They should be controlled for when effectiveness is compared across studies, ideally using pooled individual data for meta-analysis [38].

\section{Impact of recruitment and enrolment strategies}

Differences in sample characteristics are related to recruitment and enrolment strategies. In the BreathEase study, media appearance was employed throughout the study to reach the target sample size and to compensate for low referral rates from clinicians. There might have been disinterest or fears that patients using this novel service might choose to switch to other specialists or come back with new expectations, for example regarding referrals to physiotherapy. Benefits of adapting the recruitment strategy to local circumstances and the importance to have support from clinicians have been described [39, 40]. Our results underline the importance of local self-help groups and illness-specific networks as facilitator to recruitment.

All study participants, including those referred by clinicians, contacted the study centre on their own initiative, and most had learned about the study via the media. In the study by Higginson et al. [13], clinicians identified potentially eligible study participants based on information in clinical records, who were then contacted by mail through the study team. Ethical and data protection considerations did not allow for such an approach in our study. The self-referral based recruitment routes in BreathEase may have allowed for a greater focus on individual concerns related to the symptom of breathlessness and more heterogeneity in disease severity.

As part of the prolonged recruitment, all late responders were followed-up using automated prompts in the trial electronic web-based application. Time for screening was longest in those who declined participation. This may have reduced potential bias in view of the effectiveness of the intervention. HoLle et al. [41] demonstrated an example of recruitment to a population-representative survey in which late responders were less healthy and showed less favourable health behaviour.

Exclusion criteria covered logistical reasons, such as long distances to the hospital or a lack of assistance with transport to attend at least one personal appointment at the hospital. In the study by Higginson et al. [13], transport to the hospital appointment was offered. In those who declined participation, accessibility issues may also have played a role. Women were less likely to participate. This may be related to the lower likelihood of having a carer or to be living with a partner or others. Although strategies to minimise patient 
and carer burden have been suggested for effective recruitment in palliative care trials [40, 42], providing transport to the MBS would have reduced the transferability of results, as this would not be offered in routine care. Data collection was organised as home visits, so that the additional burden through study participation was time, but not related to mobility.

\section{Appraisal of study design and outcome measurement}

Pragmatic trials need high-quality outcome measures validated in this patient group [34]. Overall, the outcome measures used in our study follow the research recommendation to use a core set of validated patient and carer measures [43]. BreathEase is the first trial to use the IPOS as a primary outcome measure in addition to disease-related instruments. Relating to the logic model of the intervention (figure 1), validated and standardised outcome instruments to measure behavioural and affective psychological constructs such as self-efficacy, coping mechanisms or emotional regulation would be needed. They were not included in the BreathEase trial because they are unavailable or difficult to use in view of the patient group with advanced illness and breathlessness as a symptom. Integrating qualitative and quantitative components into the BreathEase study will allow for a better understanding and interpretation of the results of the main effectiveness study from the patients' perspective with the interaction between individual attitudes, behaviours and experiences with the multiple component service and its setting [44, 45].

Forthcoming analysis will examine whether and how attendance at the MBS was effective regarding increased mastery of breathlessness in longitudinal perspective (quantitative analysis) and the interaction between individual attitudes and behaviours and experiences with the multiple component service, its setting and context (qualitative and mixed-methods analyses). Analyses will further consider intervention fidelity, economic evaluation, patient satisfaction and the impact of adverse events on the effectiveness of the intervention.

Provenance: Submitted article, peer reviewed.

This study is registered at www.clinicaltrials.gov with identifier number NCT02622412.

Data availability: All individual patient data that underlie the results reported in this article (text, tables, figures and appendices) can be made available after anonymisation to researchers who provide a methodologically sound proposal; they will need to sign a data access agreement. Information regarding submitting proposals and accessing data is available from the corresponding author. To gain access, proposals should be directed to the corresponding author.

Conflict of interest: M. Schunk reports grants from the German Federal Ministry of Education and Research (BMBF) during the conduct of the study. U. Berger reports grants from the Federal Ministry of Education and Research (Germany) during the conduct of the study. L. Le reports grants from the German Federal Ministry of Education and Research (BMBF) during the conduct of the study. E. Rehfuess has nothing to disclose. L. Schwarzkopf reports grants from the German Federal Ministry of Education and Research (BMBF) during the conduct of the study. S. Streitwieser reports grants from the German Federal Ministry of Education and Research (BMBF) during the conduct of the study. T. Müller reports grants from BMBF (Federal Ministry of Science and Research) during the conduct of the study. M. Hofmann reports grants from the German Federal Ministry of Education and Research (BMBF) during the conduct of the study. R. Holle reports grants from the Federal Ministry of Research during the conduct of the study. R.M. Huber reports grants from German Ministry of Education and Research (BMBF) during the conduct of the study. U. Mansmann reports grants from BMBF (Federal Ministry of Science and Research) during the conduct of the study. C. Bausewein reports grants from the German Federal Ministry of Education and Research during the conduct of the study.

Support statement: The study "Randomised controlled trial testing the effectiveness of a new multi-professional Breathlessness sErvice for patients with any Advanced diSease against usual care" (BreathEase) was funded by the German Federal Ministry of Education and Research (funding phase 06/2014-05/2017, grant number 01GY1331) as part of a government grant programme to fund Interventional Trials in Health Care Research. Funding information for this article has been deposited with the Crossref Funder Registry.

References

1 Bausewein C, Booth S, Gysels $\mathrm{M}$, et al. Understanding breathlessness: cross-sectional comparison of symptom burden and palliative care needs in chronic obstructive pulmonary disease and cancer. $J$ Palliat Med 2010; 13: 1109-1118. 
Booth S, Silvester S, Todd C. Breathlessness in cancer and chronic obstructive pulmonary disease: using a qualitative approach to describe the experience of patients and carers. Palliat Support Care 2003; 1: 337-344.

3 Spathis A, Booth S, Moffat C, et al. The Breathing, Thinking, Functioning clinical model: a proposal to facilitate evidence-based breathlessness management in chronic respiratory disease. NPJ Prim Care Respir Med 2017; 27: 27.

4 Johnson MJ, Yorke J, Hansen-Flaschen J, et al. Towards an expert consensus to delineate a clinical syndrome of chronic breathlessness. Eur Respir J 2017; 49: 1602277.

5 Hutchinson A, Barclay-Klingle N, Galvin K, et al. Living with breathlessness: a systematic literature review and qualitative synthesis. Eur Respir J 2018; 51: 1701477.

6 Luckett T, Phillips J, Johnson M, et al. Insights from Australians with respiratory disease living in the community with experience of self-managing through an emergency department 'near miss' for breathlessness: a strengths-based qualitative study. BMJ Open 2017; 7: e017536.

7 Bausewein C, Schunk M, Schumacher P, et al. Breathlessness services as a new model of support for patients with respiratory disease. Chron Respir Dis 2018; 15: 48-59.

8 Booth S, Ryan R, Spathis A. Service delivery of complex interventions for refractory breathlessness. Curr Opin Support Palliat Care 2016; 10: 228-235.

9 Bausewein C, Schumacher P, Bolzani A. Integrated breathlessness services for people with chronic conditions. Curr Opin Support Palliat Care 2018; 12: 227-231.

10 Booth S, Moffat C, Farquhar M, et al. Developing a breathlessness service for patients with palliative and supportive care needs, irrespective of diagnosis. J Palliat Care 2011; 27: 28-36.

11 Farquhar MC, Prevost AT, McCrone P, et al. Is a specialist breathlessness service more effective and cost-effective for patients with advanced cancer and their carers than standard care? Findings of a mixed-method randomised controlled trial. BMC Med 2014; 12: 194.

12 Farquhar MC, Prevost AT, McCrone P, et al. The clinical and cost effectiveness of a Breathlessness Intervention Service for patients with advanced non-malignant disease and their informal carers: mixed findings of a mixed method randomised controlled trial. Trials 2016; 17: 185.

13 Higginson IJ, Bausewein C, Reilly CC, et al. An integrated palliative and respiratory care service for patients with advanced disease and refractory breathlessness: a randomised controlled trial. Lancet Respir Med 2014; 2: 979-987.

14 Schunk M, Schulze F, Bausewein C. What constitutes good health care for patients with breathlessness? perspectives of patients, caregivers, and health care professionals. J Palliat Med 2019; 22: 656-662.

15 Schunk M, Le L, Syunyaeva Z, et al. Effectiveness of a specialised breathlessness service for patients with advanced disease in Germany: a pragmatic fast-track randomised controlled trial (BreathEase). Eur Respir J 2021; 58: 2002139.

16 Rohwer A, Pfadenhauer L, Burns J, et al. Series: clinical epidemiology in South Africa. Paper 3: Logic models help make sense of complexity in systematic reviews and health technology assessments. $J$ Clin Epidemiol 2017; 83: 37-47.

17 Anderson RA, Bailey DE Jr, Wu B, et al. Adaptive leadership framework for chronic illness: framing a research agenda for transforming care delivery. ANS Adv Nurs Sci 2015; 38: 83-95.

18 Pfadenhauer LM, Gerhardus A, Mozygemba K, et al. Making sense of complexity in context and implementation: the Context and Implementation of Complex Interventions (CICI) framework. Implement Sci 2017; 12: 21.

19 Schmid-Mohler G, Caress AL, Spirig R, et al. "Thrust out of normality" - how adults living with cystic fibrosis experience pulmonary exacerbations: a qualitative study. J Clin Nurs 2019; 28: 190-200.

20 Zhang Y, Alonso-Coello P, Guyatt GH, et al. GRADE guidelines: 19. Assessing the certainty of evidence in the importance of outcomes or values and preferences - risk of bias and indirectness. J Clin Epidemiol 2019; 111: 94-104.

21 Gysels MH, Higginson IJ. Self-management for breathlessness in COPD: the role of pulmonary rehabilitation. Chron Respir Dis 2009; 6: 133-140.

22 Hillebregt $\mathrm{C}$, Vlonk A, Bruijnzeels $\mathrm{M}$, et al. Barriers and facilitators influencing self-management among COPD patients: a mixed methods exploration in primary and affiliated specialist care. Int J Chron Obstruct Pulmon Dis 2016; 12: 123-133.

23 Hsu KY, Lin JR, Lin MS, et al. The modified Medical Research Council dyspnoea scale is a good indicator of health-related quality of life in patients with chronic obstructive pulmonary disease. Singapore Med J 2013; 54: 321-327.

24 Global Initiative for Chronic Obstructive Lung Disease (GOLD). Global Strategy for Diagnosis, Management, and Prevention of COPD. 2018. Available from: http://goldcopd.org/

25 Packer M. Proposal for a new clinical end point to evaluate the efficacy of drugs and devices in the treatment of chronic heart failure. J Card Fail 2001; 7: 176-182.

26 Charlson ME, Pompei P, Ales KL, et al. A new method of classifying prognostic comorbidity in longitudinal studies: development and validation. J Chronic Dis 1987; 40: 373-383. 
27 Abernethy AP, Shelby-James T, Fazekas BS, et al. The Australia-modified Karnofsky Performance Status (AKPS) scale: a revised scale for contemporary palliative care clinical practice [ISRCTN81117481]. BMC Palliat Care 2005; $4: 7$.

28 Schünemann HJ, Puhan M, Goldstein R, et al. Measurement properties and interpretability of the chronic respiratory disease questionnaire (CRQ). COPD 2005; 2: 81-89.

29 Murtagh FE, Ramsenthaler C, Firth A, et al. A brief, patient- and proxy-reported outcome measure in advanced illness: validity, reliability and responsiveness of the Integrated Palliative care Outcome Scale (IPOS). Palliat Med 2019; 33: 1045-1057.

30 Schildmann EK, Groeneveld El, Denzel J, et al. Discovering the hidden benefits of cognitive interviewing in two languages: the first phase of a validation study of the Integrated Palliative care Outcome Scale. Palliat Med 2016; 30: 599-610.

31 Schreiner AS, Morimoto T, Arai Y, et al. Assessing family caregiver's mental health using a statistically derived cut-off score for the Zarit Burden Interview. Aging Ment Health 2006; 10: 107-111.

32 Ludwig K, Graf von der Schulenburg JM, Greiner W. German value set for the EQ-5D-5L. Pharmacoeconomics 2018; 36: 663-674.

33 Seidl H, Bowles D, Bock JO, et al. FIMA - Fragebogen zur Erhebung von Gesundheitsleistungen im Alter: Entwicklung und Pilotstudie. [FIMA - questionnaire for health-related resource use in an elderly population: development and pilot study]. Gesundheitswesen 2015; 77: 46-52.

34 Rothwell PM. External validity of randomised controlled trials: "to whom do the results of this trial apply?". Lancet 2005; 365: 82-93.

35 Afonso AS, Verhamme KM, Sturkenboom MC, et al. COPD in the general population: prevalence, incidence and survival. Respir Med 2011; 105: 1872-1884.

36 DeMeo DL, Ramagopalan S, Kavati A, et al. Women manifest more severe COPD symptoms across the life course. Int J Chron Obstruct Pulmon Dis 2018; 13: 3021-3029.

37 Samulowitz A, Gremyr I, Eriksson E, et al. "Brave men" and "emotional women": a theory-guided literature review on gender bias in health care and gendered norms towards patients with chronic pain. Pain Res Manag 2018; 2018: 6358624.

38 Brighton LJ, Miller S, Farquhar M, et al. Holistic services for people with advanced disease and chronic breathlessness: a systematic review and meta-analysis. Thorax 2019; 74: 270-281.

39 Dunleavy L, Walshe C, Oriani A, et al. Using the 'Social Marketing Mix Framework' to explore recruitment barriers and facilitators in palliative care randomised controlled trials? A narrative synthesis review. Palliat Med 2018; 32: 990-1009.

40 Newington L, Metcalfe A. Factors influencing recruitment to research: qualitative study of the experiences and perceptions of research teams. BMC Med Res Methodol 2014; 14: 10.

41 Holle R, Hochadel M, Reitmeir P, et al. Prolonged recruitment efforts in health surveys: effects on response, costs, and potential bias. Epidemiology 2006; 17: 639-643.

42 Hanson LC, Bull J, Wessell K, et al. Strategies to support recruitment of patients with life-limiting illness for research: the Palliative Care Research Cooperative Group. J Pain Symptom Manage 2014; 48: 1021-1030.

43 Brighton LJ, Tunnard I, Farquhar M, et al. Recommendations for services for people living with chronic breathlessness in advanced disease: results of a transparent expert consultation. Chron Respir Dis 2019; 16: 1479973118816448.

44 Noyes J, Hendry M, Lewin S, et al. Qualitative "trial-sibling" studies and "unrelated" qualitative studies contributed to complex intervention reviews. J Clin Epidemiol 2016; 74: 133-143.

45 Johnson RB, Schoonenboom J. Adding qualitative and mixed methods research to health intervention studies: interacting with differences. Qual Health Res 2016; 26: 587-602. 